\title{
Brain-dead kidney donor: selection, care, and administration
}

\author{
A R LUKSZA
}

British Medical fournal, 1979, 1, 1316-1319

\section{Summary and conclusions}

Over four and a half years a district general hospital provided 34 cadaveric kidneys for transplantation. All brain-dead patients were regarded as potential donors, flow charts being used to maintain circulation and urine formation and facilitate administration. With this system the time lapse between diagnosis of brain death and removal of kidneys ranged from three to six hours and ischaemia was minimised.

It is concluded that adoption of the system by other hospitals of comparable size would result in enough good-quality kidneys to satisfy present needs, thus reducing the initial high failure rate and enabling more patients to be accepted for dialysis.

\section{Introduction}

Renal transplantation is now a standard surgical procedure, yet of an estimated 2000 kidneys needed yearly in the $\mathrm{UK}^{1}$ only 700 are transplanted. ${ }^{2}$ Of these, $17 \%$ fail to function, and the proportion may be rising. ${ }^{3}$ An important factor in this high failure rate is a prolonged period of ischaemia, which probably results from inappropriate donor care.

Each year in the UK some 6000 people aged under 65 die from head injury or spontaneous subarachnoid haemorrhage 4 but only a few are considered for kidney donation. Responsibility for providing suitable kidneys lies with the medical profession, particularly clinicians in intensive care and neurosurgical units.

I describe methods of donor care that may be used in a district general hospital. They are based on four and a half years of experience at this hospital, during which 34 kidneys were donated.

\section{Selection of donors}

Every brain-dead patient with normal renal function should be regarded as a potential donor. Those aged under 5 or over 60 , however, are seldom suitable. The usual causes of death are head injury, spontaneous subarachnoid haemorrhage, cerebral tumour, resuscitated cardiac arrest with brain death, and acute self-poisoning. Patients with self-poisoning may be considered for donation only when the offending drug has been eliminated and hence is no longer contributing to the clinical state. Most kidneys are obtained from patients with subarachnoid haemorrhage and head injury and few from patients with self-poisoning or resuscitated cardiac arrest. We routinely admit all patients with spontaneous subarachnoid haemorrhage or head injury with coma to the intensive care unit. This ensures appropriate care, including maintenance of renal function.

Contraindications to donation comprise systemic infection, extracerebral malignancy, hypertension, chronic pyelonephritis, diabetes, and widespread atheroma.

Intensive Care Unit and Clinical Research Laboratory, Whiston Hospital, Prescot, Merseyside L35 5DR

A R LUKSZA, MB, MRCP, research registrar

\section{Brain death}

Brain death occurs when there is irreversible damage to the cortex and brain stem. Spontaneous breathing then stops, resulting in hypoxic cardiac arrest. When gas exchange is maintained mechanically the heart, kidneys, and liver continue to function for hours or days. The diagnosis of brain death means that the patient is dead whether or not other organs are maintained artificially. ${ }^{5}$ This has opened the way for organ removal from brain-dead, heart-beating donors, thus minimising ischaemia.

Brain death is diagnosed when all activity above the foramen magnum is shown to be absent by a series of simple bedside tests. The diagnosis cannot be considered in patients with poisoning, including drug poisoning, severe hypoglycaemia, or hypothermia. At the time of testing, the core temperature must exceed $35^{\circ} \mathrm{C}$ and there must be certainty that the clinical state is not in any way attributable to poisoning. ${ }^{6}$ For cadaveric organ transplantation the Maclennan Report ${ }^{8}$ recommended that brain death should be diagnosed separately by two doctors independent of the transplant team, one of whom must have been qualified for at least five years. Their observations should be recorded separately in the patient's notes, which may be subsequently scrutinised by a coroner.

\section{DIAGNOSIS AND CERTIFICATION}

In the absence of poisoning and hypothermia brain death is diagnosed as follows.

(1) There must be no response when the pupils are examined with a bright light in a darkened room. The size of the pupils is irrelevant but they will commonly be dilated.

(2) There must be no response to corneal stimulation with cottonwool.

(3) There must be no response to the presence of the endotracheal tube nor any evidence of cough when suction is applied to the trachea.

(4) There must be no eye movements when $20 \mathrm{ml}$ ice-cold water is injected into each ear, clear access to the drums having been established.

(5) There must be no response to painful stimuli to the head and neck-for example, supraorbital pressure and firm pinching of the ear lobes.

(6) Spontaneous breathing must be absent during hypercapnia; this may be tested in either of two ways.

(a) The ventilator is disconnected and a 2-1 reservoir bag filled with oxygen substituted. Oxygen is stopped and the pressure valve closed. The bag is then squeezed about four times a minute for three minutes. Assisted ventilation is then stopped. The bag is observed for respiratory movements, which must be absent for five minutes. Cardiac contractions cause movement of the bag synchronous with the heart beat and should not be confused with respiratory movements.

(b) Arterial carbon dioxide pressure is measured. If this is below $4.8 \mathrm{kPa}(36 \mathrm{~mm} \mathrm{Hg}$ ) alveolar ventilation is reduced to attain normocapnia. This is achieved by lowering the minute volume by reducing the frequency and either tidal volume or pressure. The concentration of inspired oxygen is increased to prevent hypoxaemia. Table I gives the predicted ventilator settings required to achieve normocapnia. After 15 minutes the patient is disconnected from the ventilator and oxygen delivered at $21 / \mathrm{min}$ through a fine cannula introduced into the trachea. The patient's chest is observed for five minutes, during which there must be no spontaneous respiratory movements.

If all the above criteria are satisfied the tests need not be repeated. If any test gives an equivocal result, however, treatment should be continued and testing repeated at four-hour intervals. Electroencephalography is not required to diagnose brain death and may even be misleading. ${ }^{9}$ Purely spinal reflexes may persist and do not preclude the diagnosis.

Protocol requires that the two doctors confirming brain death should record their observations and certification of the diagnosis in the case notes. For this purpose we use a detailed questionnaire, 
which, when completed and signed, serves as documentation of the diagnosis. Two copies are entered into the potential donor's case notes for scrutiny by coroner or transplant surgeon, who must "satisfy himself by personal examination that life is extinct."

\section{Care of donors}

Care of the brain-dead kidney donor falls into three categories: nursing care of the unconscious; maintenance of pulmonary gas exchange; and maintenance of the circulation and urine formation. ${ }^{10}$ The bladder is catheterised and a urinometer-for example, a Curity urine meter, Kendall Medical Products-used to measure output. Nursing comprises care of the airway, endotracheal suction, regular turning of the patient, and hourly measurement of blood pressure, pulse, and urine flow.

\section{PULMONARY GAS EXCHANGE}

All patients will require intermittent positive-pressure ventilation (IPPV) and have an endotracheal tube in place. Ventilation may be given by any type or make of machine. Most patients will have normal lungs, and the metabolic rate will be normal or reduced. The ventilator treatment is therefore comparable to that used during general anaesthesia without deliberate hyperventilation and in acute self-poisoning. The machine must be adjusted to avoid $(a)$ extreme hypocapnia and $(b)$ high airway pressures, which may reduce cardiac output. Extreme hypocapnia causes vasoconstriction with resulting oliguria. The machine must therefore be set at a low tidal volume and airway pressure.

Tidal and minute volumes may be set according to body weight (table I). Thus for a patient weighing $70 \mathrm{~kg}$ the tidal volume should be $500 \mathrm{ml}$ and the minute volume 6 . This will usually maintain normocapnia and avoid a high airway pressure Table I shows the amount of oxygen to be fed into the ventilator. These values will result in an inspired oxygen concentration of about $60 \%$, which will result in complete saturation of arterial blood. If IPPV causes hypotension a subatmospheric (negative) phase should be introduced into the respiratory cycle. About half the ventilators in common use have this facility. A subatmospheric phase increases venous return to the heart with a consequent rise in cardiac output and blood pressure.

TABLE I-Ventilator settings predicted to attain normocapnia at 12 respirations min. (Values obtained from nomogram constructed by Radford ${ }^{19}$ and assume normal basal metabolic rate and fixed dead space)

\begin{tabular}{cccc}
\hline $\begin{array}{c}\text { Body weight } \\
(\mathrm{kg})\end{array}$ & $\begin{array}{c}\text { Tidal volume } \\
(\mathrm{ml})\end{array}$ & $\begin{array}{c}\text { Minute volume } \\
(\mathrm{l})\end{array}$ & $\begin{array}{c}\text { Oxygen to be added } \\
\text { to inspiratory } \\
\text { circuit } \\
(1 / \text { min })\end{array}$ \\
\hline 20 & 200 & $2 \cdot 4$ & $1 \cdot 5$ \\
40 & 350 & $4 \cdot 2$ & $2 \cdot 0$ \\
60 & 450 & $5 \cdot 4$ & $2 \cdot 5$ \\
70 & 500 & $6 \cdot 0$ & $3 \cdot 0$ \\
80 & 575 & 6.9 & 3.5 \\
100 & 700 & $8 \cdot 4$ & $4 \cdot 0$ \\
\hline
\end{tabular}

\section{CIRCULATION AND URINE FORMATION}

When ventilation is appropriate attention turns to maintaining circulation and urine formation, which should exceed $1.5 \mathrm{ml} / \mathrm{min}$. Problems in managing the circulation require a logical approach and may be solved by means of a flow diagram (fig 1). When blood pressure is normal a peripheral vein is cannulated and an infusion comprising alternate bottles of colloid and dextrose with added potassium begun. In adults $500 \mathrm{ml}$ gelatin-based plasma substitute (Gelofusine or Haemaccel) and $500 \mathrm{ml} \mathrm{5 \%}$ dextrose, each with $0.5 \mathrm{~g}$ added potassium chloride, may be given hourly provided that good urinary output is maintained. No additional treatment may be required to maintain the circulation.

\section{Oliguria}

If urine output remains below $90 \mathrm{ml} / \mathrm{h}$ three manoeuvres should be tried in sequence, 30 minutes being allowed between each to assess response. Firstly, a powerful loop diuretic such as frusemide $80 \mathrm{mg}$ or ethacrynic acid $50 \mathrm{mg}$ should be given. Secondly, hypocapnia should be excluded by measuring arterial blood gases. Hypocapnia may be corrected by introducing an additional dead space into the ventilator system or reducing alveolar ventilation as described above. A dead space is simply an additional length of respirator hose, usually 15 to $20 \mathrm{~cm}$ long, inserted into the ventilator circuit between the endotracheal tube and the ventilator hoses. If the normotensive

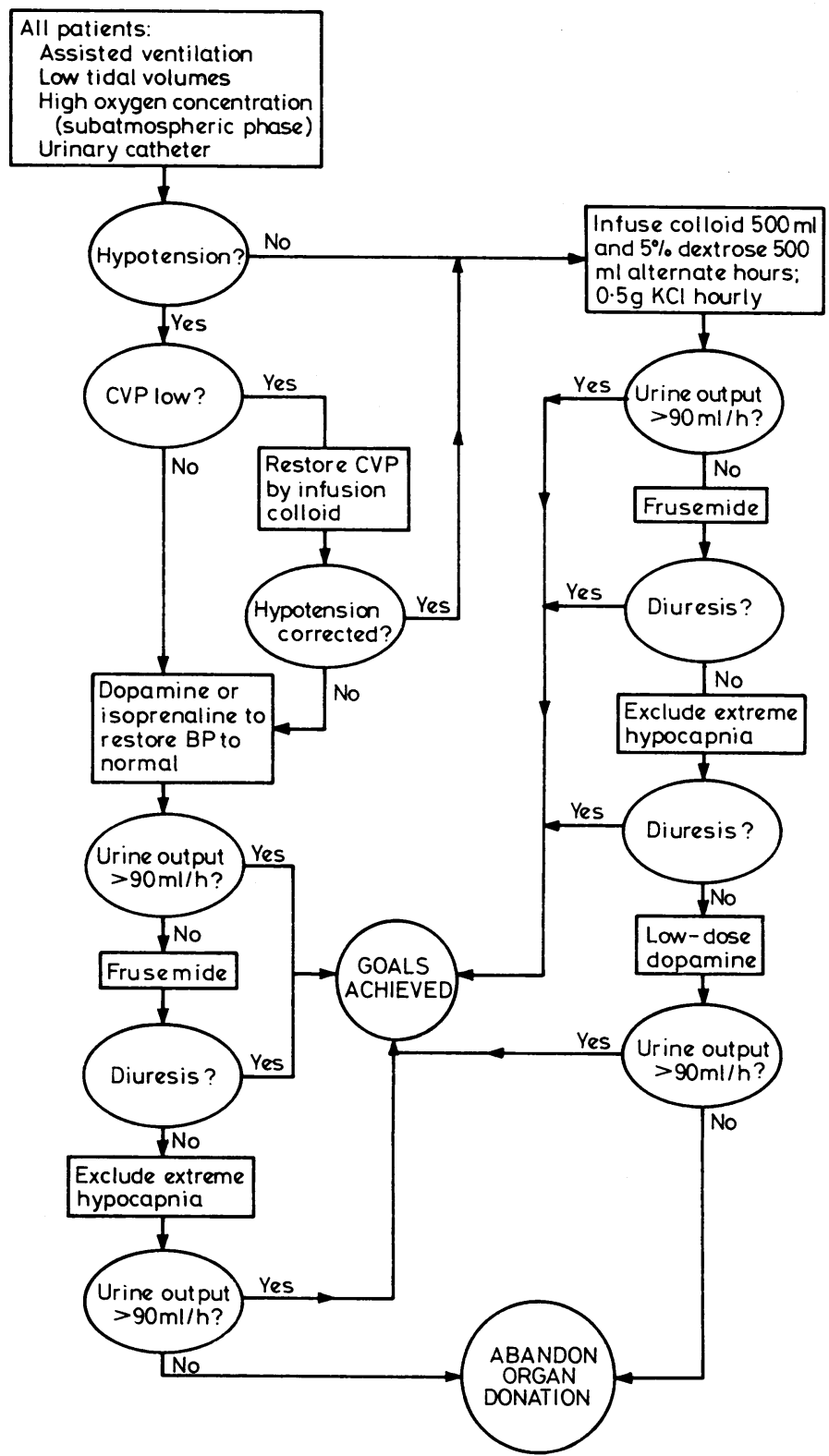

FIG 1-Flow diagram showing methods to maintain circulation and urine flow.

patient remains oliguric despite receiving a diuretic and being normocapnic dopamine may be given at low doses by continuous infusion.

Dopamine is a direct-acting sympathomimetic agent with effects on both alpha- and beta-adrenergic receptors. ${ }^{11} \mathrm{~A}$ dose of $2-5 \mu \mathrm{g} / \mathrm{kg} / \mathrm{min}$ increases renal and mesenteric blood flow with subsequent increase in urine output. At doses above $5 \mu \mathrm{g} / \mathrm{kg} / \mathrm{min}$ it acts directly on the heart, increasing cardiac output without altering myocardial oxygen consumption or heart rate. At doses exceeding $10 \mu \mathrm{g} / \mathrm{kg} / \mathrm{min}$ it causes peripheral vasoconstriction and must be combined with a vasodilator such as nitroprusside to prevent peripheral ischaemia. One $\mathrm{ml}$ containing $40 \mathrm{mg}$ dopamine is diluted with $100 \mathrm{ml} 5 \%$ dextrose in a paediatric burette. This yields a concentration of $400 \mu \mathrm{g}$ dopamine $/ \mathrm{ml}$. The infusion rate is calculated from the weight of the patient. 


\section{Hypotension}

Hypotension requires systematic investigation and treatment, which is shown in the left branch of the flow diagram (fig 1). Incorrect ventilator settings have already been excluded. Another cause may be hypovolaemia or "pump" failure or a combination of both. Pump failure may result from direct myocardial damage or central suppression of contractility. Differentiating the two mechanisms is important, and distinction may be made from the central venous pressure (CVP). ${ }^{12}$ The pressure in an intrathoracic vein or the right atrium is measured by a cannula introduced via either the median cubital, subclavian, internal jugular, or femoral vein. The procedure should be sterile with the operator prepared as for surgery. The subclavian, internal jugular, and femoral routes require special skills, and those unfamiliar with these techniques should attempt cannulation of the median cubital vein only. Every effort should be made to choose a catheter of the correct length. If the arm vein is used the catheter must be between 60 and $70 \mathrm{~cm}$ long. When the technique is correct blood may be aspirated from the catheter and the position of the tip confirmed radiologically.

Once correctly positioned the central venous catheter may be used to infuse fluids and measure CVP. Table II gives normal values reported for CVP. ${ }^{13}$ Since IPPV influences CVP, the patient should be disconnected from the ventilator while the CVP is read.

TABLE II-Reported normal values for central venous pressure

\begin{tabular}{llcc}
\hline & \multirow{2}{*}{$\begin{array}{c}\text { Point of } \\
\text { reference }\end{array}$} & \multicolumn{2}{c}{ Normal range } \\
\cline { 3 - 4 } & & $\mathrm{cm} \mathrm{H} \mathrm{H}_{2} \mathrm{O}$ & $\mathrm{mm} \mathrm{Hg}$ \\
\hline Friedman $(1966)^{*}$ & Midaxillary line & 2 to 10 & 1.5 to $7 \cdot 4$ \\
Hardaway $(1968)^{*}$ & $\begin{array}{c}\text { Midaxillary line } \\
\text { Allen }(1948)^{*}\end{array}$ & 6 to 12 & $4 \cdot 4$ to $8 \cdot 8$ \\
& Sternal angle & -1 to -7 & -0.7 to -5.2 \\
\hline
\end{tabular}

*Cited by Kelman. ${ }^{13}$

Hypovolaemia-A low CVP reflects hypovolaemia and is an indication for rapid infusion of colloid. Initially $250 \mathrm{ml}$ is given over 15 minutes and the blood pressure and CVP then reassessed. When the CVP has been restored by the infusion the blood pressure and urine flow may increase to the appropriate level. In this case no additional treatment is required.

Pump failure-Persistent hypotension with a normal or high CVP indicates pump failure, which should be treated by continuous infusion of one or more inotropic agents. Dopamine in high concentrations $(10 \mu \mathrm{g} / \mathrm{kg} / \mathrm{min}$ or greater) may be used as described. Dosage must be titrated against effect and increments must be small. An alternative to dopamine is isoprenaline, which is a sympathomimetic agent acting almost exclusively on beta-adrenergic receptors. It has a powerful stimulatory action on the heart, increasing cardiac output and rate. It also causes peripheral vasodilatation and may therefore be used alone. Its effects on blood pressure are to produce an increase in systolic pressure and a fall in diastolic pressure. Unlike dopamine, isoprenaline produces a tendency to cardiac dysrhythmias, so the electrocardiogram must be monitored. One $\mathrm{mg}$ isoprenaline is diluted in $100 \mathrm{ml} \mathrm{5 \%}$ dextrose in a paediatric burette, yielding a concentration of $10 \mu \mathrm{g} / \mathrm{ml}$. Infusion is begun at $2 \mu \mathrm{g} / \mathrm{min}$, increasing slowly until the desired effect is reached. If ventricular tachycardia supervenes isoprenaline must be stopped but may be restarted at a lower dose after five minutes. Combination with dopamine may be effective.

When blood pressure is restored urine flow may restart. If oliguria persists, however, a diuretic is given and arterial blood gases measured to exclude hypocapnia. On rare occasions oliguria persists despite the measures described, in which case organ donation is abandoned.

\section{Administration}

In this unit administration is facilitated by means of a flow diagram (fig 2), which defines the necessary steps in chronological order. It may be modified to incorporate the names of clinicians concerned together with telephone numbers. Although the flow diagram is largely selfexplanatory, five points need to be elaborated.

Investigations-As soon as a brain-dead patient is considered for donation blood is taken for estimation of urea concentration, identification of blood group, and tests for hepatitis B antigen. Two $10 \mathrm{ml}$ aliquots of clotted and heparinised blood are set aside for later

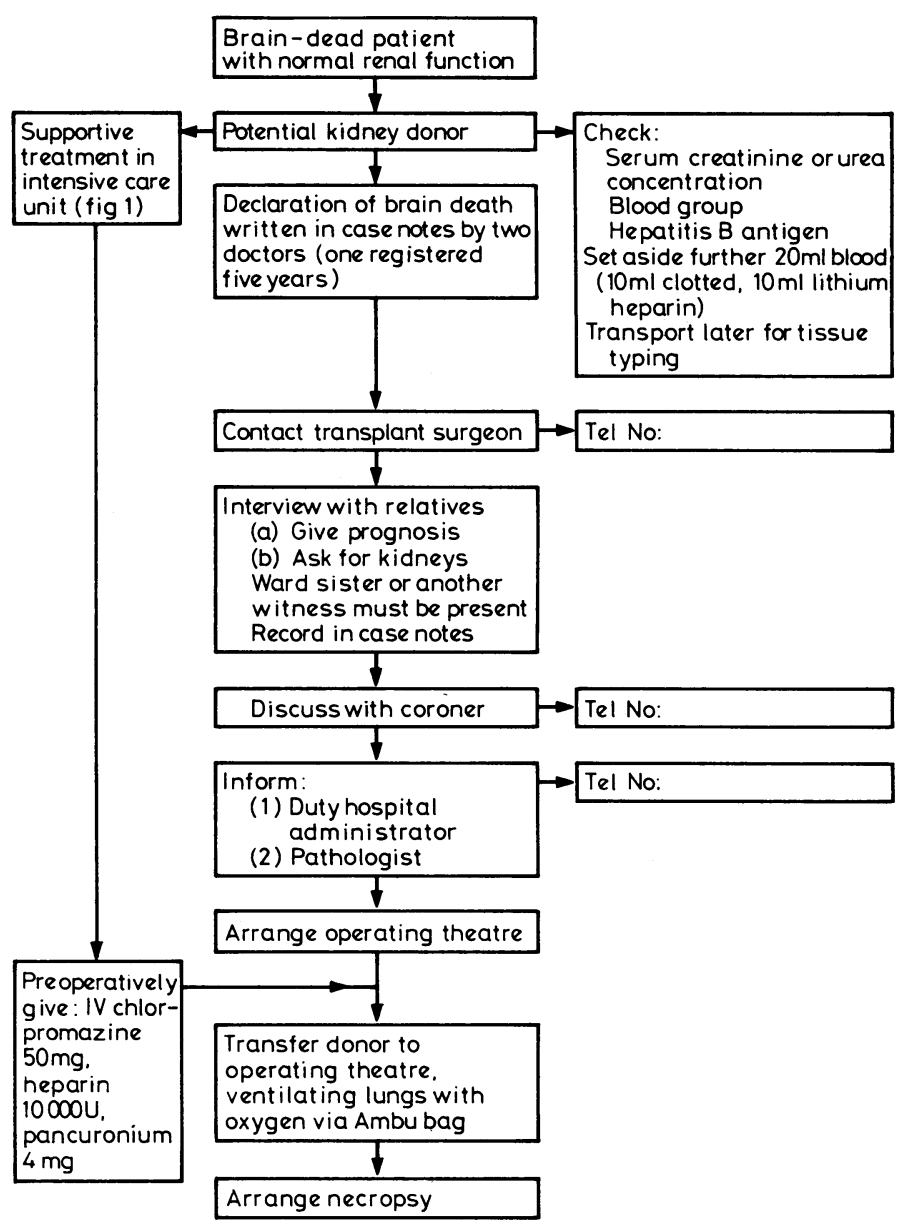

FIG 2-Flow diagram giving protocol for kidney donation.

tissue typing. If the request for donation is granted the samples are then quickly dispatched to the regional department concerned with tissue typing, usually the blood transfusion centre. The appropriate technician is informed by telephone. A catheter specimen of urine is also taken as routine to examine for infection. Although bacteriuria does not preclude donation, the result of urine culture influences later treatment of the recipient, and the transplant unit should be informed of positive results.

Consent-As provided by the Human Tissues Act $1961,{ }^{14}$ the following categories of patient may be accepted for donation. ${ }^{15} 16$ If the deceased was carrying an appropriately worded and signed "donor card" the hospital administrator may give consent for organ removal without approval of the relatives. In all other instances the permission of a close relative should be obtained and inquiry made into the possible disapproval of other members of the family. In view of the continued need for public support the kidneys should not be removed in cases of doubt. The interview with relatives is conducted by the clinician in charge of the unit, by his deputy if qualified for at least five years, or by the transplant surgeon. In our view the first two are preferable. Being readily to hand they hasten proceedings, thus allowing distressed relatives to return home sooner. Verbal consent is satisfactory so long as a witness is present, usually a registered nurse. A record of the interview is entered into the notes and signed by the clinician and witness. This will suffice as a legal record of consent.

Coroner or procurator fiscal-If death is likely to be the subject of criminal proceedings donation must not be contemplated; and if death is unnatural and could be the subject of an inquest-in the case of accident, for example-the coroner's officer must always be consulted to discuss whether donation is possible. In all other cases procedure varies from region to region and is decided by the coroner. We routinely telephone the coroner's officer whenever donation is contemplated and irrespective of circumstances in order to maintain good relations.

Drugs-Three drugs are commonly used: phenoxybenzamine, chlorpromazine, and heparin. All improve the kidney's tolerance to warm ischaemia in animal models. ${ }^{17}$ Intravenous chlorpromazine 
$50 \mathrm{mg}$ and heparin $10000 \mathrm{U}$ are given 30 minutes before the expected time of removal. Mannitol acts synergistically with both these drugs and may be included in the regimen in future. ${ }^{18}$ Phenoxybenzamine is supplied by the transplant surgeon since the drug is now available only under special licence. A single dose of $100 \mathrm{mg}$ is given intravenously five minutes before removal. A long-acting muscle relaxant such as pancuronium $4 \mathrm{mg}$ may be given at the same time to prevent contractions of the abdominal muscles at laparotomy.

Postmortem examination should be carried out on every donor to exclude occult neoplasm, which might affect the health of the recipient.

\section{Conclusion}

The techniques and laws relating to organ removal from a heart-beating donor are well known; public attitude is sympathetic, and relatives seldom refuse to give consent for donation; and statistics show that there is a surplus of potential donors. Nevertheless, the supply of viable cadaveric kidneys falls far short of the need. The fault lies with the medical profession and must be due to lack of knowledge and skills or to inappropriate attitudes of hospital medical staff. Table III lists the requirements for participation in a transplantation programme.

TABLE III-Skills, knowledge, and attitudes required for participation in transplantation programme

Skills:

Monitoring circulation

Appropriate fluid treatment

Knowledge:

Organisational protocol for donation

Legal aspects of donation

Awareness of shortage of donor kidneys

Attitudes:

Obligations versus rights

Attitudes towards organ donation/brain death/transplantation programme

The relevant knowledge and techniques have been described. Appropriate attitudes can be learned only from the example of others.

We have shown that a district general hospital can make appreciable contributions to a transplantation programme. The procedure has been facilitated by the use of flow charts. These prevent errors and simplify and hasten the procedure. In our hands the time taken from the diagnosis of brain death to the removal of kidneys ranges from three to six hours.
One estimate suggests that a small district general hospital should be able to supply six donors a year. ${ }^{1}$ We calculate that if other hospitals of comparable size were to follow our example there would be a surplus of donor kidneys. This would allow surgeons to choose only those kidneys removed under optimal conditions for transplantation. The initial high failure rate would be expected to improve. A far greater number of patients undergoing long-term dialysis could be offered transplantation and hence the chance of an improved quality of life. Moreover, with a faster turnover more patients with chronic renal failure could be accepted for dialysis.

I am grateful for the receipt of a personal grant from the research committee of the Mersey Regional Health Authority. The scheme of research is part of a project (research scheme No 366) made possible by a grant to Dr E Sherwood Jones, who helped in the preparation of the paper. I also acknowledge the help of Mr R A Sells, transplant surgeon.

\section{References}

${ }^{1}$ British Transplantation Society Report, British Medical fournal, 1975, 1, 251.

2 Sells, R A, personal communication, 1978.

${ }^{3}$ Nelson, S D, and Tovey, G M, British Medical fournal, 1974, 1, 622.

4 Office of Population Censuses and Surveys, series DH4: Mortality Statistics, 1974. London, HMSO, 1976.

5 Honorary Secretary of Conference of Medical Royal Colleges and their Faculties (UK), British Medical fournal, 1979, 1, 332.

- Conference of Medical Royal Colleges and their Faculties (UK), British Medical fournal, 1976, $2,1187$.

7 Jennett, B, fournal of Medical Ethics, 1975, 1, 63.

8 Department of Health and Social Security, Advice from Advisory Group on Transplantation Problems on the Question of Amending the Human Tissues Act 1961, Cmnd 4106. London, HMSO, 1969. (Maclennan Report.)

${ }^{9}$ Mohandes, A, and Chou, S N, fournal of Neurosurgery, 1971, 35, 211.

10 Jones, E S, Essential Intensive Care. Lancaster, MTP Press, 1978.

11 Martindale, W, The Extra Pharmacopoeia, 27th edn. London, Pharmaceutical Press, 1977.

12 Farman, J V, British fournal of Clinical Equipment, 1978, 2, 210.

13 Kelman, G R, Anaesthesia, 1971, 26, 209.

14 Human Tissues Act 1961. London, HMSO, 1961

15 Skegg, P D G, Cambridge Law fournal, 1974, 33, 130

${ }^{16}$ Skegg, P D G, Medicine, Science and the Law, 1974, 14, 53.

17 Bell, P R F, Quin, R O, and Calman, K C, Transplantation Proceedings, 1974, 6, 245.

18 Pentlow, B, Transplantation. In press.

19 Radford, E P, Fournal of Applied Physiology, 1955, 7, 451.

(Accepted 23 March 1979)
Abuse of the hallucinogenic mushroom Psilocybe semilanceata was described by Hyde et al. ${ }^{1}$ I report a case in which persistent panic attacks developed after eating psilocybin mushrooms.

\section{Case report}

A 24-year-old man presented to the outpatient department with a threemonth history of attacks of tension, anxiety, fear that something was about to befall him, depersonalisation, palpitations, bounding pulses, dryness of the mouth, and "butterflies in the stomach." Sometimes the attacks were accompanied by disturbed vision-"everything becomes misty, as though I am looking into a fog." Two weeks before onset he had eaten 25 psilocybin mushrooms in the company of friends in a pub, where he had drunk two pints of beer. Three hours later he had become emotionally labile. One of his friends had asked, "Where's Howard ?" He repeated the question twice. "Then I reeled back. It was all black behind him. The whole room blacked out then cleared in seconds." The patient felt well next day.
The first attack occurred while the patient was talking to workmates on the first day of a new job and lasted for a quarter of an hour. He had a further attack that evening. Episodes occurred daily since then. He controlled the symptoms with lorazepam $2.5 \mathrm{mg}$, without which they could have lasted all day and into the night. Chlorpromazine $50 \mathrm{mg}$ twice daily had no effect.

The patient had no other psychiatric history. He described a happy childhood and life and was socially well adjusted. In the months before his illness he had been subjected to stress in interpersonal relations. He had eaten psilocybin mushrooms on two other occasions and smoked cannabis infrequently - all without ill effect. Since the onset of his illness he had felt suicidal several times.

\section{Comment}

Psilocybin is a class A drug under the Misuse of Drugs Act 1971. Charges have been brought for possessing the mushroom. Judge Blomefield ruled at Reading Crown Court in 1976 that because the mushroom itself is not mentioned in the Act possession is not an offence. In September 1977 Goodchild successfully appealed to the law lords against a conviction for possessing a marijuana plant, albeit without the flowers and fruiting tops iher. mentioned by the Act. 